SEXUAL FUNCTION

\title{
Who reports sexual function problems? Empirical evidence from Britain's 2000 National Survey of Sexual Attitudes and Lifestyles
}

\author{
C H Mercer, K A Fenton, A M Johnson, A J Copas, W Macdowall, B Erens, K Wellings
}

See editorial on $\mathrm{p} 364$

Sex Transm Infect 2005;81:394-399. doi: 10.1136/sti.2005.015149

See end of article for authors' affiliations .....................

Correspondence to: Dr Catherine H Mercer, Centre for Sexual Health and HIV Research, Department of Primary Care and Population Sciences, University College London, Mortimer Market Centre, off Capper Street, London WCIE 6AU, UK; cmercer@gum. ucl.ac.uk

Accepted for publication 1 April 2005
Objective: To identify sociodemographic, sexual, and health behavioural and attitudinal factors associated with reporting sexual function problems.

Methods: A probability sample survey of 11161 men and women aged 16-44 years resident in Britain in 2000. Data collected by a combination of computer assisted face to face and self interviewing. Outcomes were self report of a range of sexual function problems, considered as "any problems" $(1+$ lasting 1+ months in the past year) and "persistent problems" (1+ lasting 6+ months in the past year), and associations with sociodemographic, behavioural, and attitudinal variables.

Results: Both "any" and "persistent" sexual function problems were more commonly reported by women than men. A variety of sociodemographic factors were associated with both measures but differed by gender. For example, the adjusted odds ratio (AOR) for reporting any problems for married $v$ single respondents was 0.70 (95\% confidence interval (Cl) 0.57 to 0.87 ) v 1.31 (95\% Cl 1.10 to 1.56 ) for men and women, respectively. Sexual behaviours significantly associated with reporting sexual function problems included competence at first sex, paying for sex in the past 5 years, number of occasions of sex and masturbation, both in the past 4 weeks. For men (only), reporting STI diagnosis(es) was significantly associated with reporting "any" problems (AOR 2.1, 95\% Cl 1.4 to 3.2) and "persistent" problems (AOR $2.1,95 \% \mathrm{Cl} 1.1$ to 3.9). Both measures were significantly more likely among men and women who reported communication difficulties with their partners, with AORs in excess of 1.9.

Conclusions: Sexual fulfilment is an important part of sexual health. Understanding factors associated with reporting sexual problems, and recognising that such factors maybe partnership specific, is an important step towards improving our understanding of sexual function and thus improving the provision of care and support available.
$\mathrm{R}$ ecent sexual health policy developments in Britain have focused on adverse outcomes of sexual behaviour such as sexually transmitted infections (STI), including HIV/ AIDS, and unintended pregnancy. Relatively little attention has been paid in the past to sexual fulfilment or function, despite their strong association with quality of life. ${ }^{1-4}$ It is, nevertheless, being increasingly recognised and expressed that sexual fulfilment should also be seen as an important part of sexual health. ${ }^{5}$ Indeed, the English government's 2001 Strategy for Sexual Health and HIV stated in principle that "essential elements of good sexual health are equitable relationships and sexual fulfilment."

We have previously estimated the prevalence of a range of self reported sexual function problems using a national probability sample, the 2000 National Survey of Sexual Attitudes and Lifestyles (Natsal 2000). ${ }^{7}$ We discriminated between the different components of the sexual "dysfunction" spectrum and considered problems in terms of those lasting at least 1 month in the past year, as well as problems lasting at least 6 months in the past year, the latter which we termed "persistent problems." We demonstrated that "any" sexual function problems were common, reported by approximately half of women and one third of men, but that smaller proportions reported "persistent" problems (6.2\% of men and $15.6 \%$ of women). ${ }^{7}$ Despite the relatively high prevalence of sexual function problems among sexually active young people, we observed that while many people avoid sex because of their sexual problems, few people seek help for their problems. Identifying sociodemographic, sexual, and health behavioural and attitudinal factors associated with reporting sexual function problems is an important step towards improving our understanding of sexual function and thus improving the provision of care and support available for people experiencing sexual problems. In this paper we consider a number of such factors using data from Natsal 2000 and examine their association with reporting "any" and "persistent" sexual function problems.

\section{METHODS}

Natsal 2000 is a stratified probability sample survey of 11161 men and women aged 16-44 years, resident in private households in Britain, who were interviewed between May 1999 and February 2001. The response rate was 65.4\%. Details of the methodology are published elsewhere. ${ }^{8}{ }^{9}$

Respondents were asked a range of questions about their sexual lifestyles and attitudes including, in a computer assisted self interview (CASI) component, questions about their experience of sexual problems. The questions were based on those used in the US National Health and Social Lifestyle Survey (NHSLS), ${ }^{2}$ which measured the main dimensions of sexual dysfunction as defined in the International Classification of Diseases tenth revision (ICD10)..$^{12}{ }^{10}$ The questions in Natsal 2000 were worded":

In the past year, have you experienced any of the following for 1 month or longer?

Abbreviations: AOR, adjusted odds ratio; CASI, computer assisted self interview; Natsal, National Survey of Sexual Attitudes and Lifestyles; NHSLS, National Health and Social Lifestyle Survey; STI, sexually transmitted infections 
$1 \quad$ Lacked interest in having sex

2 Felt anxious just before having sex about your ability to perform sexually

3 Were unable to come to a climax (experience an orgasm)

4 Came to a climax (experience an orgasm) too quickly

5 Experienced physical pain during intercourse

6 Had trouble achieving or maintaining an erection (men only)

$7 \quad$ Had trouble lubricating (women only).

A positive response to any of these elicited further questions regarding duration, whether respondents had avoided sex in the past year because of their problem(s), and from whom, if anyone, they had sought help in the past year.

The population for this study is all respondents who reported at least one heterosexual partnership in the year before interview (87.5\% of men and $89.3 \%$ of women). ${ }^{9}$ We examined the association between reporting sexual problems and reporting heterosexual partnership(s) in the year before interview and observed that those who reported no heterosexual partnership(s) were less likely to report problems. The selection criteria may thus result in a slight overestimation of the prevalence of sexual problems.

All analyses were performed using Stata version 7.0 to account for stratification, clustering, and weighting of the sample. ${ }^{11}$ The data were weighted to correct for unequal selection probabilities and to match the age/sex population profile. ${ }^{90}$ We used logistic regression to examine the association between sexual problems and a number of sociodemographic, sexual, and health behavioural and attitudinal factors. The crude and adjusted odds ratios (OR) are given along with the corresponding 95\% confidence interval (CI). The adjusted OR (AOR) considers the association after controlling for age and marital status. Statistical significance is considered at $\mathrm{p}<0.05$ for all analyses. We note that because the data are from a cross sectional survey it is not possible to determine causality, with some factors likely causes of sexual problems, while other factors likely consequences of sexual problems.

We obtained ethical approval from University College Hospital, North Thames Multicentre, and all local research ethics committees in Britain.

\section{RESULTS}

As previously reported, women were significantly more likely than men to report at least one sexual function problem lasting at least 1 month in the past year, as well as "persistent" sexual function problems $(\mathrm{p}<0.0001){ }^{7}$ Table $\mathrm{l}$ explores sociodemographic factors associated with reporting "any" and "persistent" problems. There was no clear association for either gender between age and reporting sexual problems lasting at least 1 month in the past year. In contrast, reports of persistent problems increased significantly with increasing age for both men and women. Married and cohabiting men were significantly less likely to report any sexual problems than single men (AORs: 0.70 and 0.67 , respectively). In contrast, married and cohabiting women were significantly more likely to report sexual problems lasting at least 1 month than single women (AORs: 1.31 and 1.29 , respectively). Marital status was not however associated with reporting persistent problems for either gender after adjusting for age. Women with young children in the home were significantly more likely to report problems (AORs approximately 1.4 for both "any" and "persistent" problems). There were no significant associations for either gender with either ethnicity or education.
Respondents defined as not "competent at first sex" (see table 2 for definition) were significantly more likely to report any sexual problems (AORs: 1.28 and 1.34 for men and women, respectively) and persistent problems (AORs: 1.63 and 1.55 for men and women, respectively). Those who reported that they "found it difficult to talk about sex with any partner" were significantly more likely to report any and persistent problems (AORs of approximately 2 for men and in excess of 2 for women). Reporting masturbation in the past 4 weeks was also significantly associated with reporting sexual problems for both men and women, as was reporting that they would like sex much or a bit more often. Reporting fewer than four occasions of sex in the past 4 weeks, which corresponds to the median number of occasions of sex in the past 4 weeks, ${ }^{8}$ was significantly associated with reporting sexual problems for both men and women. Men who reported to have paid for sex in the past 5 years were significantly more likely to report sexual function problems lasting at least 1 month in the past year, but not persistent problems (AORs of 1.57 and 0.79 , respectively). Reporting more than one partner, relative to only one partner in the past year, was not associated with either measure of sexual function problems for either gender.

Among the health factors considered (table 3), men who perceived their health as bad or very bad were more likely to report "any" and "persistent" sexual function problems (AORs of 1.91 and 2.98, respectively), as were men who had been diagnosed with a STI in the past 5 years (AOR of 2.08). Similar associations with these health factors were observed for women, but only for "any" problems, and then, only of borderline statistical significance. Alcohol consumption, in terms of whether or not the respondent reported consuming more than the recommended number of units per week, was associated for men (AOR 1.33) but not for women. Being overweight, defined as having a body mass index of at least 25 , was not significantly associated with either measure of sexual function problems.

\section{DISCUSSION}

In this large, nationally representative survey of sexual behaviour in a young population, reporting sexual function problems is relatively common and is associated with a number of sociodemographic, sexual and health behavioural and attitudinal variables. The prevalence of reporting sexual function problems is significantly higher in women, relative to men, as others have reported. ${ }^{12}$ Furthermore, we observed that associations (for example, with the presence of young children in the home, and marital status) were not always in the same direction for men and women. In accordance with other studies, we also found some association with age, ${ }^{12} 12$ having young children in the home, ${ }^{13}$ but contrary to others' findings, no significant association with education was observed for either men or women. ${ }^{12}$ As we have noted, it is not possible to make causal inference from these cross sectional survey data, but the association between our measure of sexual competence at first intercourse ${ }^{14}$ and sexual function in later life may suggest that positive first sexual experiences may have lasting consequences for sexual experience and satisfaction. The association with communication with partners may also have implications for the sex education curriculum as well as implications for relationship, education, and counselling. This result also highlights how, in some cases, sexual function problems are often not an individual's problem but that they maybe partnership specific, such that it maybe important to consider an individual's partnership(s) in the "treatment" or "management" of some sexual function problems.

In common with the US study, ${ }^{12}$ we used a small number of general questions covering the main components of the ICD-10 


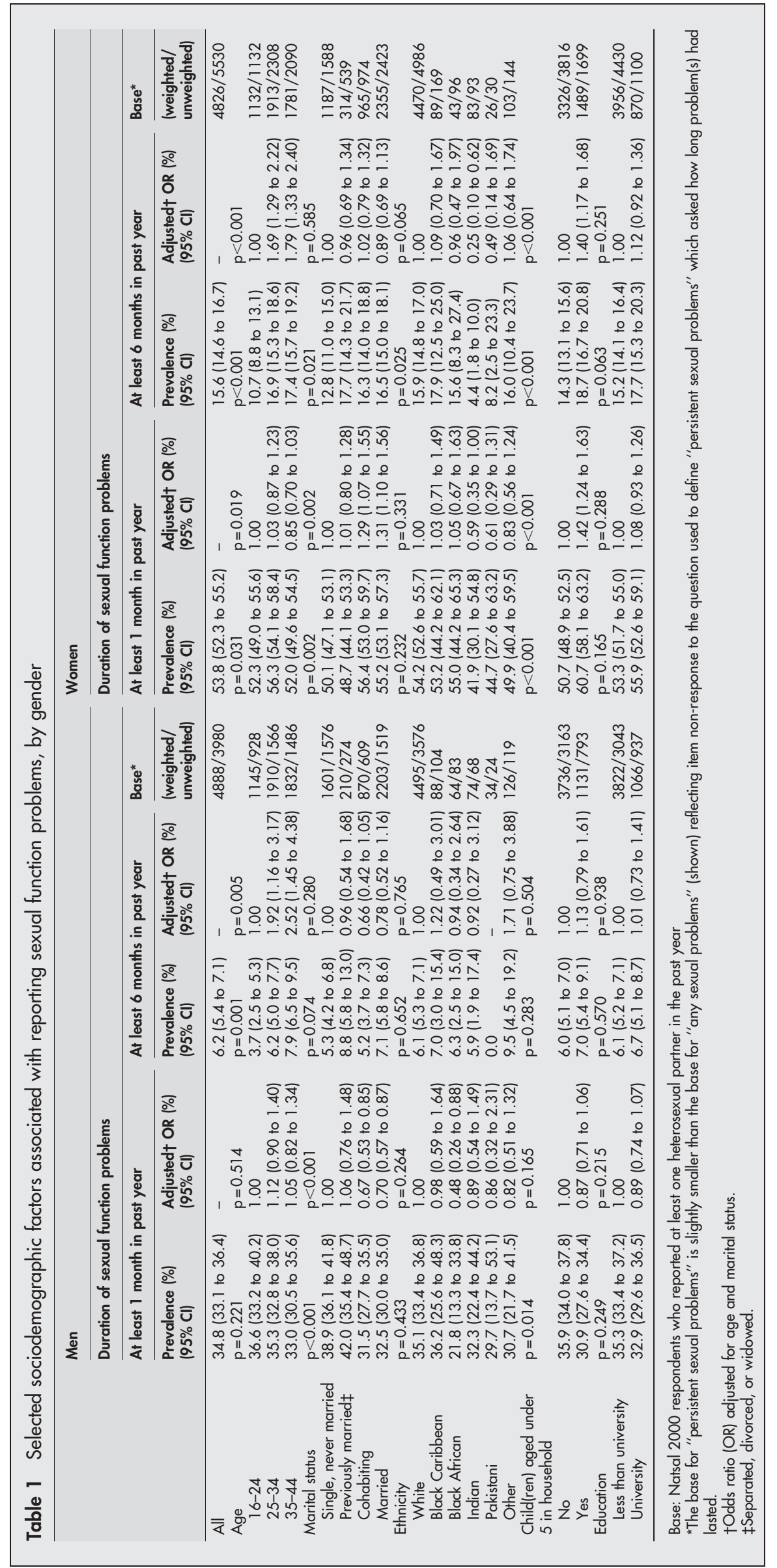




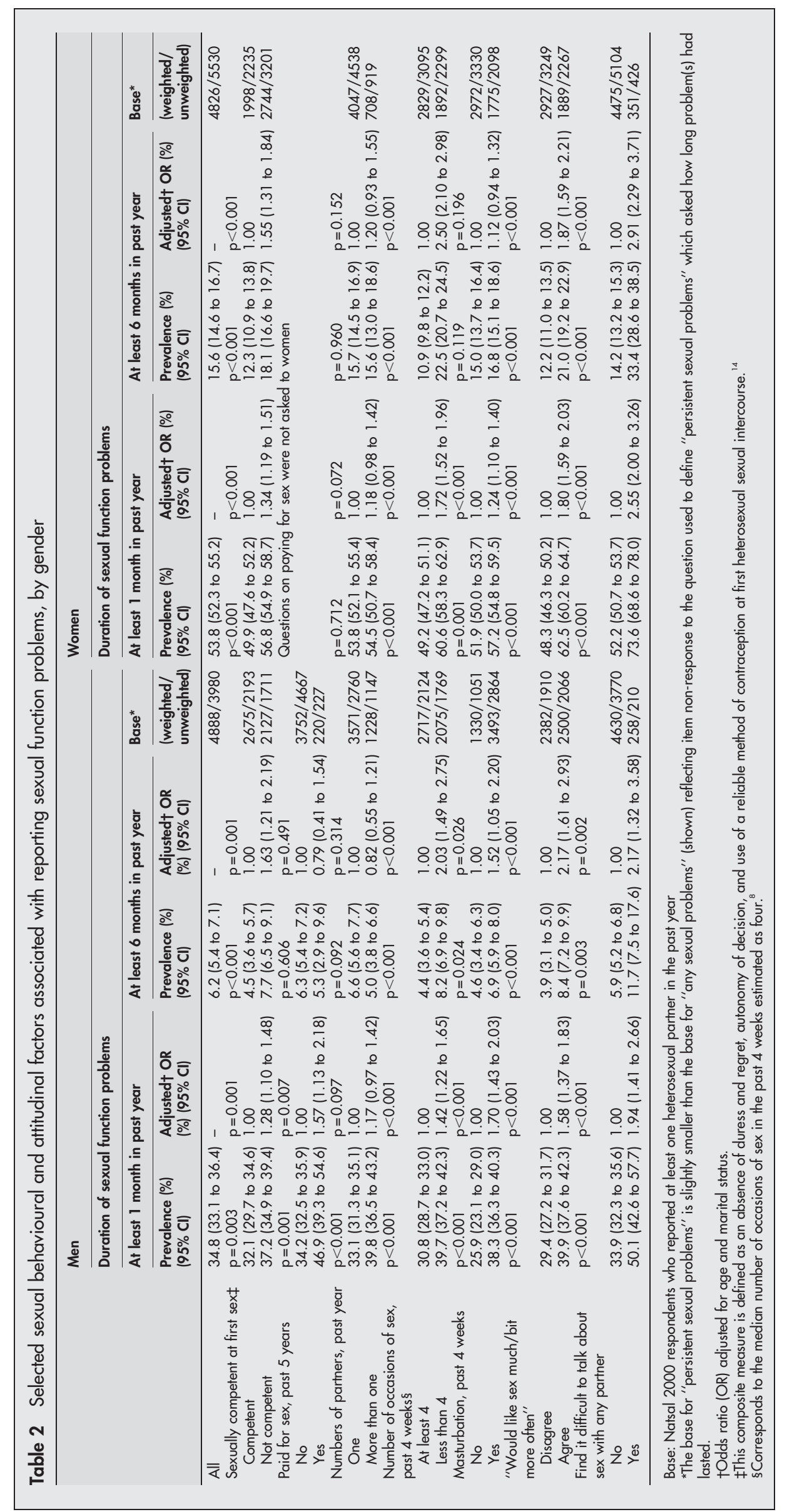




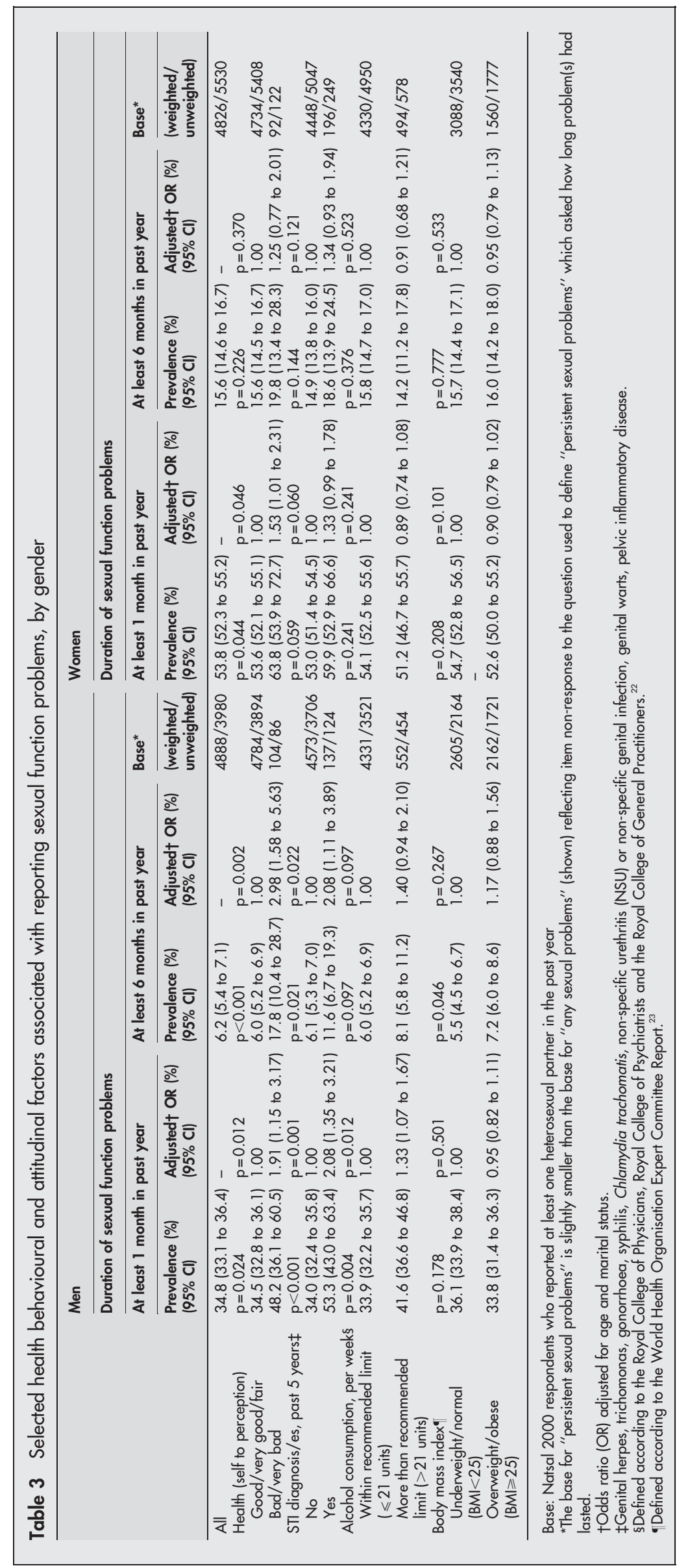


classification of sexual dysfunction, ${ }^{10}$ but this is broad, and covers a spectrum of expressed problems that, in turn, are potentially attributable to social, relationship, psychological, and physical factors and the interplay between them. This contrasts with detailed clinical measures of sexual dysfunction-for example, the Golombok-Rust Inventory of Sexual Satisfaction (GRISS) Scale, ${ }^{15}{ }^{16}$ and the more detailed questions possible in smaller scale studies specifically focused on sexual problems. ${ }^{17}$ Thus, given the broad spectrum of problems, we have not sought to define clinical "dysfunction," rather self reported experience of sexual function problems in the general population. However, as we have previously acknowledged, ${ }^{7}$ it is necessary to question whether a lack of interest in sex, the most commonly reported problem lasting at least 1 month in the past year, " can be considered as "dysfunction," or even a problem, given its relatively high prevalence. Although it is worth noting that men and women in Natsal 2000 who reported this "problem" were significantly more likely to report that they "would like sex much" or "a bit more often" than those people who did not report a lack of interest in sex $(58.2 \%$, $95 \%$ CI $54.0 \%$ to $62.2 \%$, v $49.7 \%$, $95 \%$ CI $47.8 \%$ to $51.6 \%$, $\mathrm{p}=0.0003$, and $47.0 \%, 95 \%$ CI $44.7 \%$ to $49.3 \%, v 33.9 \%, 95 \%$ CI $32.1 \%$ to $35.7 \%$, p $<0.0001$, of men and women, respectively), suggesting that lacking interest in sex maybe perceived as a problem for these individuals. In this respect, it is necessary to question the extent to which self perceived "dysfunction" is influenced by the media, ${ }^{18}{ }^{19}$ which some argue has increased our expectations of our own and our partner's abilities. ${ }^{20}$

The factors considered in this paper are not exhaustive, partly because they are from a large, general population survey of sexual behaviour; none the less, this paper has identified a number of common factors associated with self reporting sexual function problems. The findings from our paper are relevant to those working in sexual health policy and practice at local and national levels. Awareness of the discrepancy between men and women in terms of their experience of sexual function problems, particularly with regard to their marital status, is likely to help those involved in the provision of psychosexual counselling, as will the identification of partner communication as a crucial factor associated with sexual function. Our data also support emphasising the importance of establishing positive initial experiences of sexual behaviour, and this should help to guide provision of appropriate sex education. Finally, our data underline the importance of remaining vigilant in more general health related consultations of the need to consider the possible relation between sexual function and more general health status and health behaviours, as has been recently recommended. ${ }^{21}$

\section{Key messages}

(1) Reporting sexual function problems is significantly associated with a number of sociodemographic, health related, sexual behavioural, and attitudinal factors

(2) These significant associations are not always in the same direction for men and women, perhaps reflecting gender differences in the nature of problems

(3) The perceived importance of sexual function problems to an individual will vary, and in some cases, may be partnership specific

(4) Identifying factors associated with reporting sexual function problems and their relation to other health problems is an important step towards improving our understanding of sexual function and the provision of support available

\section{ACKNOWLEDGEMENTS}

We thank the study participants, the team of interviewers and operations, and computing staff from the National Centre for Social Research who carried out the interviews.

\section{CONTRIBUTORS}

CM was the lead writer of this paper and undertook all the statistical analysis; $\mathrm{KF}, \mathrm{AJ}, \mathrm{BE}$, and $\mathrm{KW}$ were principal investigators and participated in the design and management of the main study and preparation of this manuscript; AC and WM advised on the interpretation of the data and contributed to the drafting of the manuscript.

\section{Authors' affiliations}

C H Mercer, A M Johnson, A J Copas, Centre for Sexual Health and HIV Research, Department of Primary Care and Population Sciences, University College London, Mortimer Market Centre, off Capper Street, London WCIE 6AU, UK

K A Fenton, HIV/STI Department, Health Protection Agency, Centre for Infections, 61 Colindale Avenue, London NW9 5EQ, UK

W Macdowall, K Wellings, London School of Hygiene and Tropical Medicine, Keppel Street, London WCIE 7HT, UK

B Erens, National Centre for Social Research, 35 Northampton Square, London ECIV OAX, UK

Funding: The study was supported by a grant from the Medical Research Council with funds from the Department of Health, the Scottish Executive, and the National Assembly for Wales.

Conflict of interests: None declared.

\section{REFERENCES}

1 Laumann EO, Gagnon JH, Michael RT, et al. The social organisation of sexuality: sexual practices in the United States. Chicago: University of Chicago Press, 1994.

2 Laumann EO, Paik A, Rosen RC. Sexual dysfunction in the Unites States. Prevalence and predictors. JAMA 1999;281:537-44.

3 Goldmeier D. Sexual dysfunction in genitourinary medicine clinics. Int J STD AIDS 2000;11:191-2.

4 Goldmeier D, Judd A, Schroeder K. Prevalence of sexual dysfunction in new heterosexual attenders at a central London genitourinary medicine clinic in 1998. Sex Transm Infect 2000;76:208-9.

5 Goldmeier D. Female low sexual desire and sexually transmitted infections. Sex Transm Infect 2001;77:293-4.

6 Department of Health. National strategy for sexual health and HIV. London: Department of Health, 2001

7 Mercer CH, Fenton KA, Johnson AM, et al. Sexual function problems and help seeking behaviour in Britain: national probability sample survey. BMJ 2003;327:426-7.

8 Johnson AM, Mercer CH, Erens B, et al. Sexual behaviour in Britain: partnerships, practices, and HIV risk behaviours. Lancet 2001;358:1835-42.

9 Erens B, McManus S, Field J, et al. National survey of sexual attitudes and lifestyles II: Technical Report. London: National Centre for Social Research, 2001.

10 World Health Organization. International statistical classification of diseases and related health problems, 10th revision. Geneva: WHO, 1992.

11 StataCorp. Stata statistical soffware: release 7.0. Texas: Stata Corporation, 2001.

12 Dunn KM, Croft PR, Hackett Gl. Association of sexual problems with social, psychological, and physical problems in men and women: a cross-sectional population survey. J Epidemiol Commun Health 1999;53:144-8.

13 Barrett G, Pendry E, Peacock J, et al. Sexual function after childbirth. Br J Obstet Gynaecol 1998;105:242-3.

14 Wellings K, Nanchahal K, Macdowall W, et al. Sexual behaviour in Britain: early heterosexual experience. Lancet 2001;358:1843-50.

15 Rust J, Golombok S. The GRISS: a psychometric instrument for the assessment of sexual dysfunction. Arch Sex Behav 1986;15:157-65.

16 Meston CM, Derogatis LR. Validated instruments for assessing female sexual function. J Sex Marital Ther 2002;28:155-64.

17 Nazareth I, King M, Boynton P. Problems with sexual function in people attending London general practices. BMJ 2003;327:423.

18 Keane FEA, Carter P, Goldmeier D, et al. The provision of psychosexual services by genitourinary medicine physicians in the United Kingdom. Int J STD AIDS 1997;8:402-4.

19 Kell P, Curless E. Who should look after patients with sexual dysfunction? Why genitourinary physicians are ideally placed. Int J STD AIDS 2001;12:351-2.

20 Hart G, Wellings K. Sexual behaviour and its medicalisation: in sickness and in health. BMJ 2002;324:896-900.

21 Medical Foundation for AIDS and Sexual Health. Recommended standards for sexual health services. London: Medical Foundation for AIDS and Sexual Health, 2005.

22 Royal College of Physicians, Royal College of Psychiatrists and the Roya College of General Practitioners. Alcohol and the heart: sensible limits reaffirmed. London: Royal College of Physicians, 1995.

23 World Health Organization Expert Committee. Physical status - the use and interpretation of anthropometry. WHO Technical Report Series 854. Geneva: WHO, 1995. 